\title{
Is visiting for the patient or the relative?
}

\author{
Jessica Inch \\ BJARN Editor
}

$\Lambda$ few weeks ago, whilst on shift in our postanaesthetic care unit (PACU), two relatives to the desk asking to visit their mother, who had only returned from theatre around $20 \mathrm{~min}$ before. She was a 'high risk' patient, with cardiac history and previous post-operative complications. Our visitation policy allows around $10 \mathrm{~min}$ with recovery patients and they had been advised to wait down stairs and 'get a coffee' when on the phone to us earlier, but appeared $10 \mathrm{~min}$ later with chocolates and flowers. It was decided that, since they were at the desk they

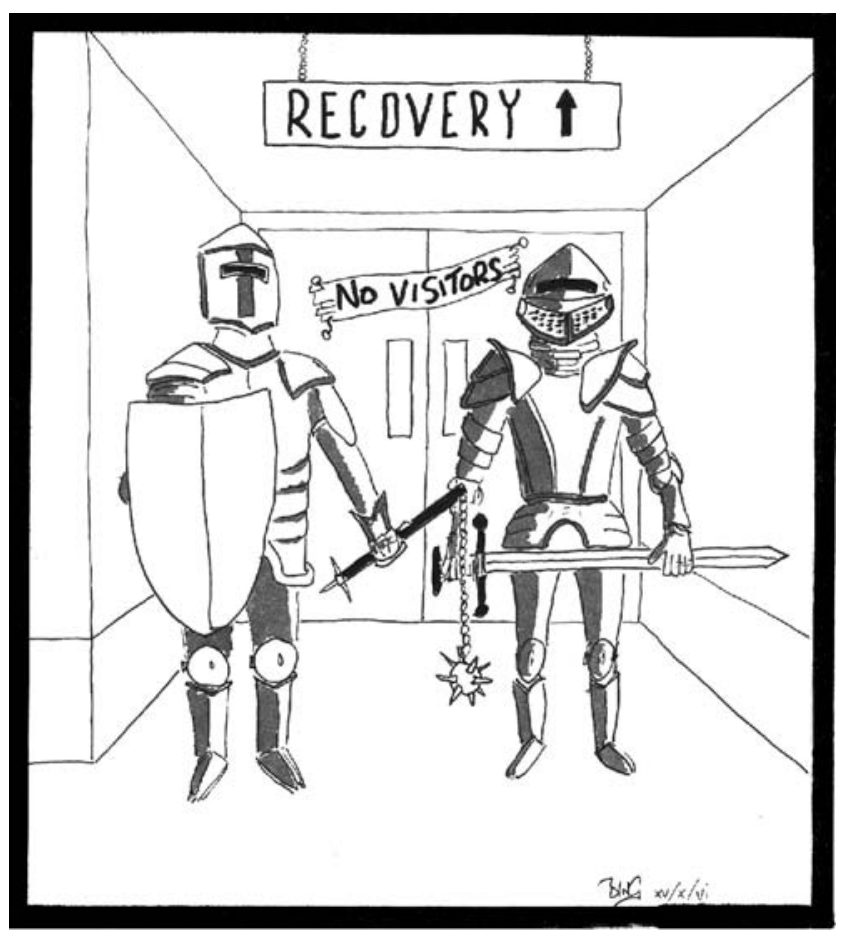

should see her for a few minutes. 'That's great, come on guys' one said as seven others came around the corner, trailing children, giant balloons and a rather large menacing 'Get Well' bear. Needless to say they were asked to visit only in small groups and that they could only have a few minutes each. However, nobody actually asked the patient if she wanted to see her entire extended family and by the third pair of visitors she was starting to get very tired. When they were asked to cut short the visit by the staff, the patient then became more anxious stating that they had 'come such a long way' and didn't want to disappoint them.

A number of themes emerge from this situation. More than ever these days, patients and indeed their relatives are demanding more information about the care that they are receiving in our hospitals. I personally find this frequently is manifesting itself in relatives wanting more time with their loved ones in hospital, both before an operation and immediately afterwards. I am sure we have all had those patients like the one discussed above, whose relatives are braking down the door in their hordes, only to leave the patient, tired and a little stressed out. I certainly will confess to, at times feeling that visiting is an intrusion especially when pressurised to allow it out of designated hours. So when do we decide that it is appropriate for a patient to be visited in the recovery, if at all and indeed is it our question to ask? I have always been aware of a conflict in attitude towards visitation between staff and in some hospitals can become quite a controversial area of discussion, leaving it subjectively down to the nurse in charge at the time, which I sometimes feel is unfair on the patient.

When I first started thinking about this issue, I believed the answer to be simple. If the individual specifically requests visitors in the PACU then effort should be made 
to cater for their wishes. However, for years my opinion had swung dramatically between visitors being allowed as soon as the patient is conscious, to only once they are on a main ward. I have worked with many different policies, varying from strictly no visiting in the recovery, to it being entirely down to the patient, with there being obvious advantages for both policies.

These days patients are more informed of their choices and encouraged by the NHS to take 'ownership' of their circumstances within the system, such as the 'choose and book' process of choosing your own hospital for elective surgery. Yet some of us may be taking away this 'ownership' at a vital stage when enforcing visitation rules.

An incident that will always stay with me from my training comes from an elderly lady who had undergone surgery which required a longer than usual stay in the recovery/high dependency area. When asked if she needed anything, she told of how much she missed her dog. When the notes were studied further, it appeared that her elderly husband and only son had been killed in a car accident a few years previously and she had no close family near by. Despite the obvious difficulties, the ward sister went to great effort and arranged a suitable situation which briefly allowed her to see her dog. She was the most grateful patient I have ever met and I believe her good recovery was down to her positivity after seeing her pet.
Visiting policies have taken an unfortunate route in the US and is currently a hot topic of discussion. Since $9 / 11$, hospitals allowing open visiting have been forced to switch to restricted times as relatives are now viewed as a possible security risk for large city hospitals. This has resulted in tighter rules and a heavier security presence. There are reports of it therefore becoming a stressful time for staff and patients.

Is allowing visiting in the recovery room the epitome of patient centred care, or is it the wrong time and wrong place for relatives? Does it stop us getting on with our patient care? I know for a fact that there are some very strong opinions regarding perioperative visiting and I would love to hear your thoughts and feelings about this. What policies if any do you have in your areas and what are your own personal experiences of how well they work. Get in touch.

The next issue of this publication is planned as a cardiac issue and is a great opportunity for you to submit any interesting case studies or other forms of articles pertaining to this vast area of our work. Do not hesitate to contact me to discuss any ideas you have at jessinchbarna@hotmail.co.uk. 